\title{
Dynamic Modeling of a Vibrating Screen Considering the Ore Inertia and Force of the Ore over the Screen Calculated with Discrete Element Method
}

\author{
Manuel Moncada M. (iD) ${ }^{1,2}$ and Cristian G. Rodríguez $\left.{ }^{1}\right)^{1}$ \\ ${ }^{1}$ Department of Mechanical Engineering, University of Concepción, Edmundo Larenas 219, 4070409 Concepción, Chile \\ ${ }^{2}$ Department of Metallurgical Engineering, University of Concepción, Edmundo Larenas 285, \\ 4070371 Concepción, Chile
}

Correspondence should be addressed to Manuel Moncada M.; manuelmoncada@udec.cl

Received 14 September 2018; Accepted 28 October 2018; Published 4 December 2018

Academic Editor: Giuseppe Ruta

Copyright (C) 2018 Manuel Moncada M. and Cristian G. Rodríguez. This is an open access article distributed under the Creative Commons Attribution License, which permits unrestricted use, distribution, and reproduction in any medium, provided the original work is properly cited.

\begin{abstract}
Vibrating screens are critical machines used for size classification in mineral processing. Their proper operation, including accurate vibration movement and slope angle, can provide the benefits of energy savings and cost reductions in the screening process and the whole mining process. Dynamic models of the vibrating screen movement available in the literature do not simulate ore motion or its interaction with screen decks. The discrete element method (DEM) allows for the calculation of the dynamic of the ore. In this paper, two 2D three-degrees-of-freedom dynamic models for a vibrating screen are tested, using linear and nonlinear approaches for angular displacement. These models consider the inertia of the ore and the ore force calculated with DEM. A double-deck linear motion vibrating screen is simulated using the DEM software LIGGGTHS. DEM is used to obtain the ore parameters in the steady state and the force on the screen decks. Two cases are compared: Case 1 considers the ore as moving together with the vibrating screen, and Case 2 considers the ore force on the screen deck as calculated by DEM. Simulations are carried out with data for an industrial vibrating screen used in copper mining. The force over the screen is significantly different between the cases. Case 1 produces a force that is unrealistic because the ore cannot produce a high-amplitude adhesion force over the screen decks. In Case 2, no adhesion force acts between the ore and deck. It is concluded that the linear dynamic model used in Case 2 is adequate to evaluate the influence of the ore on the movement of the vibrating screen. The linear dynamic model considering the force as in Case 1 can be used to simulate a vibrating screen, as long as a correct calibration parameter is included to obtain an accurate motion amplitude.
\end{abstract}

\section{Introduction}

Size classification of particulate materials is an important process in mineral processing [1], particularly in the copper industry. Vibrating screens are frequently used to separate granulated ore materials based on particle size for particles with diameters greater than $0.5 \mathrm{~mm}[2]$. In the copper industry, the most commonly used vibrating screens have linear motion and horizontal, sloped, or multisloped (banana) screens [3]. A vibrating screen has one or more screening surfaces (decks) with square or rectangular openings, and its vibratory movement depends on a system of unbalanced masses. The appropriate type of vibration allows for better movement of ore and stratification of minerals [4].

Vibrating screens are critical machines prone to successive failures that can result in huge economic losses [5] and must be constantly improved in order to meet the requirements of the mining industry [6]. Proper operation of this machine has important benefits for the whole mineral process [7], and for this reason, many studies have been conducted to investigate the behavior and operational parameters for successful operation. For example, a change 
in the slope of $1^{\circ}$ can cause a decrease of $1-2 \%$ in the screening efficiency $[1,8,9]$, whereas a change of $1 \mathrm{~mm}$ in the vibration amplitude can cause a loss of between $5 \%$ and $10 \%$ of the screening efficiency $[1,9,10]$. These efficiency losses depend on the vibrating screen design, ore characteristics, and operational conditions. Inadequate classification produces undersize particles in an oversize stream (overflow) entering a comminution process, resulting in extra energy expenditure and obstruction of the grinding by packing of fines [11]. Inadequate classification in a closed circuit produces a short circuit of the undersize stream and results in recirculating a constant percentage of fine ore in the circuit. To ensure proper operation and high performance, it is necessary to have a dynamic model that is able to predict movement of the deck to maintain or increase throughput.

The literature presents several models and studies covering different aspects of vibrating screens. Models of screens using a probabilistic approach [12, 13], stratification and passage in the screening process [14], particle movement [15-19], screen blocking [20], finite elements $[5,21-24]$, crushing plants $[7,25]$, and phenomenological models [26] can be found in the literature. Dynamic models of vibrating screens can simulate motion of the vibrating screen structure and show good agreement with experimental measurements [27] and finite element method (FEM) results [22]. The linear model proposed by $\mathrm{He}$ and Liu [28] considers three degrees of freedom. The excitation force is circular, and the vibrating screen structure is supported by symmetrical damping springs with equal stiffness. Liu et al. [29] developed a linear model with three degrees of freedom in $3 \mathrm{D}$ that has an excitation force in the vertical direction and different damping spring stiffnesses in each support position. Their study focused on vibrating screen fault diagnosis by performing a dynamical simulation on when the supports lose stiffness. Liu et al. [30] proposed a linear model similar to that developed by $\mathrm{He}$ and Liu [28] by incorporating a quadruple excitation mechanism into the model. The model proposed by Baragetti and Villa [22] considers motion in a plane with three degrees of freedom. Their model was used to calculate the dynamical response and natural frequencies, and the optimization used FEM and experimental measurements. Using that model, Baragetti [31] patented a new design for a vibrating screen. For optimum screening performance, the angular displacement was set equal to zero and held constant over time, and the load eccentricity was also made null. Thus, the resulting equations have two degrees of freedom. Slepyan and Slepyan [32] and Zahedi and Babitsky [33] analyzed a vibrating screen operating with parametric resonance, using a linear model with damping and a tensile force [32]. They employed a nonlinear dynamic model with a system of autoresonant control [33]. Peng et al. [34] developed a model with a single degree of freedom for a large vibrating screen that considered the bending and random vibration in the design of these machines, and in which the ore was simulated as a random force. Jiang et al. [27] proposed a linear dynamic model of a single-deck equal- thickness vibrating screen. In their results, the simulated amplitudes of the vertical and horizontal motion deviated by less than $5 \%$ from the corresponding experimental results. Wang et al. [19] developed a nonlinear dynamic model of a planar reciprocating vibrating screen and employed a matrix method to derive the equation of motion in order to analyze the motion of a particle on the screen. With dynamic simulation software, Jiang et al. proposed a new design of a vibrating screen, where its screen decks are composed by rigid-flexible rods [35].

These linear models [27-30] assume that the angular motion of the vibrating screen is low and implement linearization as $\sin \theta \approx \theta$ and $\cos \theta \approx 1$, which is useful under nominal operating conditions where angular displacement is not significant. However, in practice, significant angular motion occurs in vibrating screens during startup [31], shutdown, and under off-design operating conditions [3]. The nonlinear models $[19,33]$ have been developed for particular types of vibrating screens and thus are not always applicable to the vibrating screens normally used in the copper industry, due to its deck material or type of movement.

Rodríguez et al. [3] developed a 2D nonlinear dynamic model of a vibrating screen with three degrees of freedom that allows for significant angular motion and damping in which the nonlinearity is geometric due to angular displacement. They proposed a range of admissible loss of stiffness as a percentage of nominal stiffness in order to ensure proper operation using orbital analysis. The calculated stiffness range was found to be $38 \%$ on the feed side and $46 \%$ on the discharge side. Moncada and Rodríguez [36] used a nonlinear model [3] to calculate the effects of loss of stiffness in the supporting positions on the steady and transient responses of a vibrating screen. For the steady response, the change in orbital direction was analyzed, while the transient response analyzed the change in the natural frequencies due to loss of stiffness in the supporting positions.

Simulations carried out with full-ore loads $[3,19,36]$ assume that the ore has the same movement as the vibrating screen, i.e., the ore is added to the decks, approaching this force to the ore inertial force $-M_{\text {ore }} a_{\mathrm{cm}}$, where $M_{\text {ore }}$ is the mass of the ore and $a_{\mathrm{cm}}$ is the acceleration of the center of mass of the ore. This produces an unrealistic attractive force when the ore is in its highest position (ore cannot pull the vibrating screen deck) or in the free-fall phase or when throwing index is equal to zero $[15,17]$.

Because the force generated by the ore material over the decks is inaccurate owing to the impossibility of traction or a pulling force over the deck, this study aims to calculate the ore force over a vibrating screen deck by means of simulations using the discrete element method (DEM). This method considers the interaction of each particle with each other and with decks and allows forces for different simulation conditions to be obtained. Furthermore, this method is widely used in the literature. In the mining field, several machines and processes have been simulated using DEM, including cone crushers [37], mills [38], hopper discharge [39], jaw crushers [40], feed boxes [41], and 
vibrating screens [1, 8-10, 42-51]. Cleary et al. [42, 43] performed a DEM analysis of an industrial double-deck banana screen for a range of peak accelerations and two feed size distributions. Dong et al. [44] conducted a numerical analysis of the particle flow on a banana screen and demonstrated the importance of operational parameters like the slope angle of each deck, vibration amplitude, and frequency. Zhao et al. [9] carried out a numerical study of the motion particulates follow along a circularly vibrating screen deck using 3D-DEM. They studied the effects of vibration amplitude, throwing index, and screen deck inclination angle on the screening process. Fernandez et al. [45] used a one-way coupled model of smoothed particle hydrodynamics (SPH) and DEM to simulate large banana screens. DEM was used for the coarse particulate flow, while SPH was employed to model the transport of the fine particle slurry. Delaney et al. [46] used DEM to investigate the flow of a granular material over a horizontal vibrating screen, and performed a quantitative comparison between laboratory scale experiments and the simulation results. Liu et al. [47] simulated the particle flow on a banana screen deck using DEM and investigated the effects of slope angle and deck length on the screening process. Dong et al. [48] simulated the screening of particles for different vibration modes (linear, circular, and elliptical) and studied the resulting motion and penetration of the particles on the screen deck. Li et al. [49] used DEM to optimize the design and operational parameters of a linear vibrating screen. Jahani et al. [10] investigated the screening performance of banana screens using the DEM solver LIGGGHTS. An industrial double-deck banana screen with five panels and two laboratory single-deck banana screens with three and five panels were simulated, and the effects of design parameters such as the slope angle of decks, vibration amplitude, and frequency were analyzed. Their results were validated with partition numbers obtained from the literature [44]. Zhao et al. [50] quantitatively compared DEM results and experimental data for a specially designed circularly vibrating screening model under a range of operating conditions. Jafari and Nezhad [8] studied the effects of different parameters on process efficiency and mesh wear using LIGGGHTS. Dong et al. [51] conducted a numerical analysis of the effects of aperture shape, length, and orientation on particle flow and separation in a vibrating screen process. Zhao et al. [1] analyzed the combined effects of vibration parameters on a circularly screening processes. With a DEM simulation, the effects of various design and operating variables on the efficiency of screen were investigated using open-source LIGGGHTS solver with spheral and irregularly shaped particles [52]. Particle velocity, mass of oversized material, screening efficiency, and impact force were studied to reflect the performance of vibrating screen [53].

From this review of DEM simulations, we can summarize the following: (i) there is significant evidence that vibratory parameters are important for proper screening performance [1, 8-10, 42-44, 47, 52, 53]; (ii) DEM simulations do not consider the effects of ore mass flow on amplitude movement although mass flow affects amplitude [54, 55] and efficiency depends on amplitude $[1,9,10,42,43,52,53]$; and (iii) DEM simulations do not focus on vibration. Most models use circular motion even when there are experimental data showing that the motion is not circular. In addition, rotation is neglected [19], which significantly affects the movement described for the vibrating screen supports.

The dynamic simulations in this study make two different assumptions or considerations. In Case $1[3,36]$, the ore moves together with the screen deck, which means that physically the ore adheres to the screen and there is no relative displacement between them. For modeling, parameters such as the mass of the vibrating screen with the load and the position of center of mass must be calculated. In Case 2, interaction between the ore and the screen deck is represented by a time vector force for each degree of freedom $(x, y$, and, $\theta)$. Movement of the ore is simulated with DEM to obtain the force over the screen deck, and this force is then used in the calculation of the dynamic model.

In this study, a 2D linear model with three degrees of freedom that considers ore inertia and the ore force over the screen calculated using discrete element method is developed in order to determine the influence of the ore on the movement of a vibrating screen. For cases 1 and 2, DEM is used to simulate a double-deck vibrating screen. The DEM simulation is carried out in LIGGGHTS and is used to obtain ore parameters and the ore force on the screen over time. Finally, the two dynamical responses are compared.

\section{Dynamic Model}

The dynamic model for a linear motion vibrating screen has three degrees of freedom in the plane $x y$, as shown in Figure 1(a) in its equilibrium position. The excitation force of the system is time-dependent on amplitude, $F \sin (\Omega t)$, has a constant direction, $\alpha$, with respect to the line linking points $A$ and $B$, is applied at a distance, $p$, from the center of mass, and has $\Omega$ excitation frequency. The structure of the vibrating screen and all its components is defined as a rigid body inclined at an angle, $\beta$, with a center of mass located at a distance, $h$, perpendicular to segment $\overline{A B}$. Supports are located at points $A$ and $B$ and consist of a horizontal and vertical spring and damper, each at a distance, $a$ and $b$, from a projection of the center of mass, and with a stiffness, $K$, and damping, $C$. Figure 1(b) presents the degrees of freedom of the model-horizontal displacement, $x$, vertical displacement, $y$, and angular displacement, $\theta$.

For the simulation cases in this study, two approaches for modeling the ore are used. In Case 1, the ore is modeled as a rigid body and vibrate together with the screen deck. Therefore, the mass, $M$, inertia, $I$, and position of the center of mass of the vibrating screen with a load are the sum of the empty vibrating screen plus the ore. In the second case, the ore movement is calculated by DEM simulation. The load is represented in the dynamic model by a time vector force with three components for each degree of freedom: $F_{x, \text { dem }}(t), F_{y, \text { dem }}(t)$, and $F_{\theta \text {,dem }}(t)$, applied at the center of mass of the vibrating screen. 


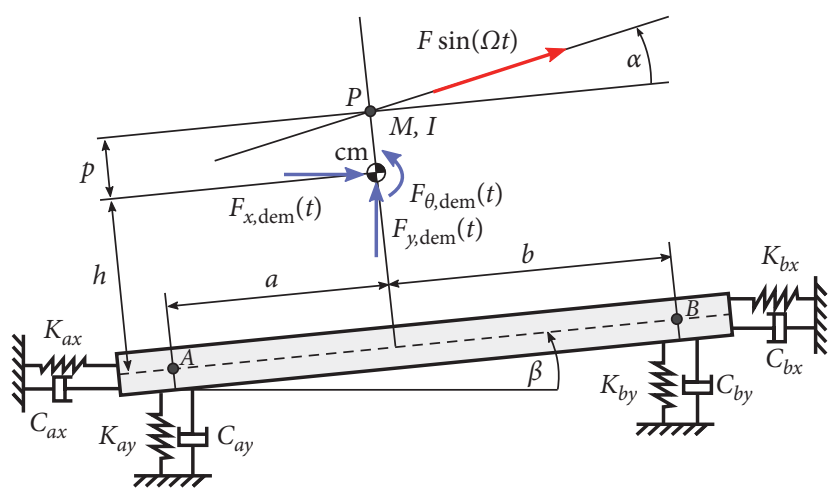

(a)

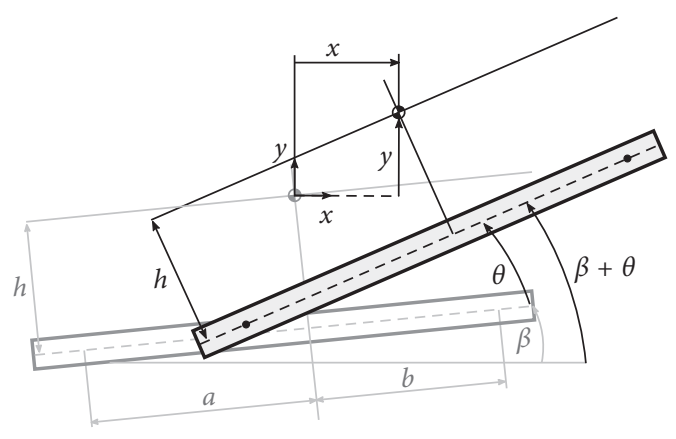

(b)

FIGURE 1: Model geometry: (a) equilibrium position and (b) degrees of freedom.

2.1. Parameters for Case 1. Parameters for the ore particles in the DEM simulation must be known in order to perform the dynamical simulations in Case 1. For that purpose, the mass, $m_{i}$, radius, $r_{i}$, inertia, $I_{i}$, and position $\left(x_{i}, y_{i}\right)$ of every particle in the $N$ particles system are used in equations (1a)-(1f) to obtain the load parameters. These load parameters include the total mass, $M_{\text {ore }}$, inertia, $I_{\text {ore }}$, position of the ore center of mass $\left(x_{\mathrm{cm}, \text { ore }}, y_{\mathrm{cm}, \text { ore }}\right)$ relative to the axes $\left(x_{\mathrm{dem}}, y_{\mathrm{dem}}\right)$, and position relative to the vibrating screen $\left(a_{\text {ore }}\right.$ and $\left.h_{\text {ore }}\right)$. Figure 2 shows a vibrating screen modeled as a rigid body, along with the upper and lower deck, feeder chute, particles, and variables used in these equations. It also illustrates the geometry to allow comparison of the dynamic modeling and DEM, and it should be noted that the variable $x$ in the dynamic modeling and $x_{\mathrm{dem}}$ in the DEM modeling have different directions. The subscript $\mathrm{cm}$ represents the center of mass, ore represents the ore load over the screen decks, em represents the empty vibrating screen, msh represents the screen deck, and low and up represent the lower and upper decks, respectively.

$$
\begin{gathered}
M_{\text {ore }}=\sum_{i=1}^{N} m_{i} \\
x_{\mathrm{cm}, \text { ore }}=\frac{1}{M_{\text {ore }}} \sum_{i=1}^{N} m_{i} \cdot x_{i} \\
y_{\mathrm{cm}, \text { ore }}=\frac{1}{M_{\text {ore }}} \sum_{i=1}^{N} m_{i} \cdot y_{i} \\
I_{\text {ore }}=\sum_{i=1}^{N} m_{i} r_{i}^{2}+m_{i}\left(\left(x_{i}-x_{\mathrm{cm}, \text { ore }}\right)^{2}+\left(y_{i}-y_{\mathrm{cm}, \text { ore }}\right)^{2}\right) \\
a_{\text {ore }}=a_{\mathrm{em}}+b_{\mathrm{em}}+c-\frac{x_{\mathrm{cm}, \text { ore }}}{\cos (\beta)} \\
h_{\text {ore }}=\frac{y_{\mathrm{cm}, \text { ore }}-y_{\mathrm{msh}, \mathrm{low}}}{\cos (\beta)}-\left(h_{\mathrm{msh}, \mathrm{low}}-h_{\mathrm{em}}\right) .
\end{gathered}
$$

With these load data, the parameters for the vibrating screen with a load can be obtained using equations (2a)(2g). Figure 2 also shows this situation, illustrating the position of vibrating screen center of mass without a load or empty, em, with a ore load, ore, and the new position of the center of mass of the vibrating screen with a load, represented without subscripts. The average values of $M, I, h$, and $a$ in steady state are used in the model.

$$
\begin{aligned}
M= & M_{\mathrm{em}}+M_{\text {ore }}, \\
a= & \frac{M_{\mathrm{em}} \cdot a_{\mathrm{em}}+M_{\text {ore }} \cdot a_{\text {ore }}}{M}, \\
b= & a_{\mathrm{em}}+b_{\mathrm{em}}-a, \\
h= & \frac{M_{\mathrm{em}} \cdot h_{\mathrm{em}}+M_{\text {ore }} \cdot h_{\text {ore }}}{M} \\
I= & I_{\mathrm{em}}+I_{\text {ore }}+M_{\mathrm{em}} \cdot\left[\left(h_{\mathrm{em}}-h\right)^{2}+\left(a_{\mathrm{em}}-a\right)^{2}\right] \\
& +M_{\mathrm{ore}} \cdot\left[\left(h_{\mathrm{ore}}-h\right)^{2}+\left(a_{\mathrm{ore}}-a\right)^{2}\right], \\
\tilde{d}= & \frac{p_{\mathrm{em}}+h_{\mathrm{em}}}{\tan \alpha}-a_{\mathrm{em}}, \\
p= & (\tilde{d}+a) \tan \alpha-h .
\end{aligned}
$$

2.2. Forces in Case 2. The force calculated with DEM, $\mathbf{F}_{\mathrm{dem}}$, is the force of all the particles over the screen decks. Applying Newton's second law to the $N$ particles system results in the following:

$$
\mathbf{F}_{\mathrm{dem}}^{\prime}+\sum_{i=1}^{N} m_{i} \cdot \mathbf{g}=\sum_{i=1}^{N} m_{i} \cdot \mathbf{a}_{i}
$$

where $\mathbf{F}_{\mathrm{dem}}^{\prime}$ is the force of the screen decks over the particles, $m_{i}$ is the mass of a particle, $\mathbf{g}=-9.81 \mathrm{~m} / \mathrm{s}^{2} \mathrm{j}$ is the gravitational acceleration, and $\mathbf{a}_{i}$ is the acceleration of each particle. 


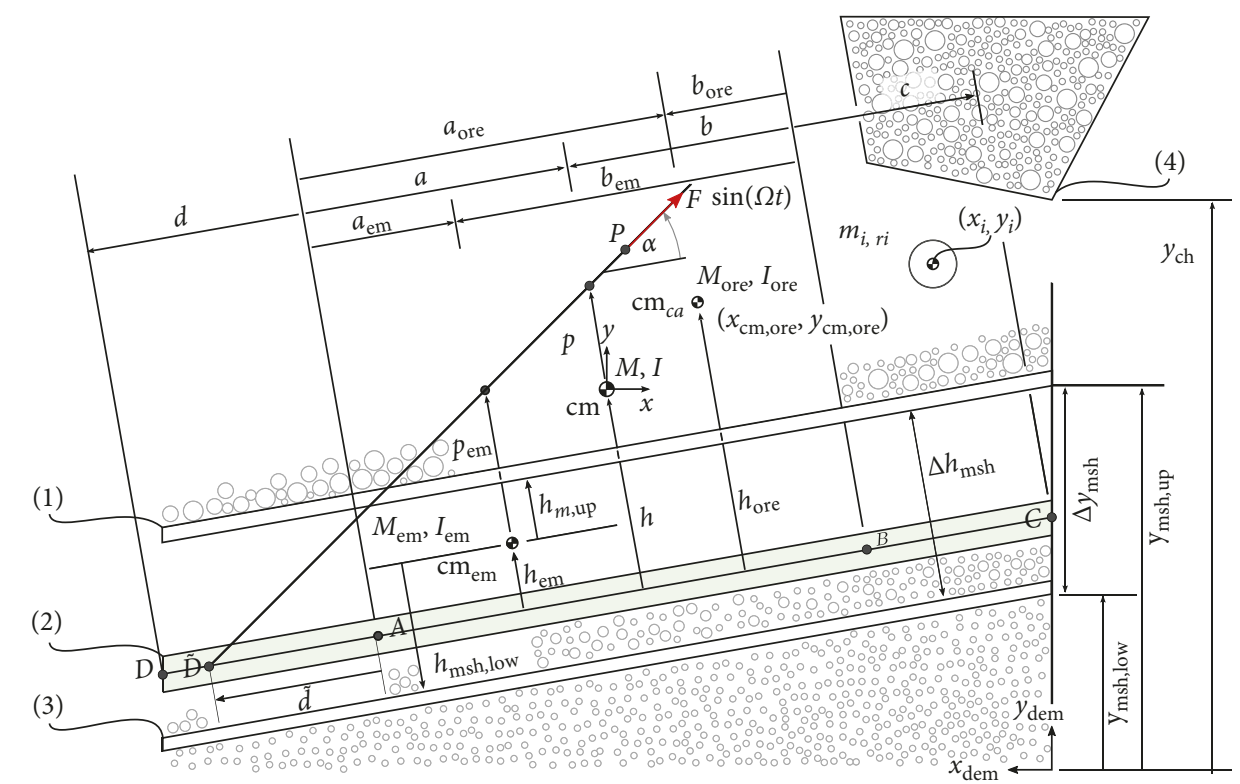

FIGURE 2: Geometric comparison of dynamic modeling and DEM, showing the change in the center of mass due to the load, with (1) upper screen deck, (2) rigid-body model, (3) lower screen deck, and (4) feed chute.

Therefore, using Newton's third law, the force of the particles over the screen decks is

$$
\mathbf{F}_{\mathrm{dem}}=-\sum_{i=1}^{N} m_{i} \cdot \mathbf{a}_{i}+\sum_{i=1}^{N} m_{i} \cdot \mathbf{g} .
$$

As $\mathbf{F}_{\mathrm{dem}}$ includes the inertial force of the particles, Case 2 also represents the dynamic characteristics of the particles. This force is applied to the vibration screen center of mass and parameters for the vibrating screen in empty conditions are used.

2.3. Equations of Motion. The equations of motion are developed using Lagrange's equations. Applying the linearization $\sin \theta=\theta$ and $\cos \theta=1$, the resulting linear equations of motion are given in equations (5)-(7). These three equations correspond to a second-order linear system of equations, and can be solved using the Newmark method with a constant time step. The nonlinear model used for simulations where the angular displacement is significant is presented in Appendix [3]. In these equations, nonlinearity is present in the terms $\dot{\theta} \sin \theta, \dot{x} \cos \theta$, and $\cos 2 \theta$, among others. For the force direction, nonlinearity is present in terms that consider a change in $\theta$, as can be seen in the term $\cos (\theta+\alpha+\beta)$.

$$
\begin{gathered}
M \ddot{x}+\dot{x} \cdot\left(C_{a x}+C_{b x}\right)+x \cdot\left(K_{a x}+K_{b x}\right) \\
=F \sin (\Omega t) \cos (\alpha+\beta)+F_{x, \mathrm{dem}}(t), \\
M \ddot{y}+\dot{y} \cdot\left(C_{a y}+C_{b y}\right)+y \cdot\left(K_{a y}+K_{b y}\right) \\
=F \sin (\Omega t) \sin (\alpha+\beta)+F_{y, \mathrm{dem}}(t),
\end{gathered}
$$

$$
\begin{aligned}
I \ddot{\theta} & -\dot{x}\left(a C_{a x}+b C_{b x}\right) \sin \beta+\dot{y}\left(a C_{a y}-b C_{b y}\right) \cos \beta \\
& -x\left(a K_{a x}+b K_{b x}\right) \sin \beta+y\left(a K_{a y}-b K_{b y}\right) \cos \beta \\
& +\dot{\theta}\left(a^{2} C_{a x}+b^{2} C_{b x}\right) \sin \beta+\theta\left(a^{2} K_{a y}+b^{2} K_{b y}\right) \cos \beta \\
& =-F \sin (\Omega t) p \cos \alpha+F_{\theta, d e m}(t) .
\end{aligned}
$$

The equations of motion are developed in an equilibrium position with an inclination angle, $\beta$. If the position of the center of mass or amount of mass changes, the vibrating screen will experience a variation in its equilibrium position, the slope $\beta$. A free-body diagram calculation allows the new slope of $\beta$ to be determined before these changes occur. This is useful when a loss of stiffness exists in the support system [36].

\section{DEM}

The discrete element method was originally developed by Cundall and Strack in 1979 [56] and it has proven to be an effective numerical technique for calculating particle movement in granular material flows. It is also useful for obtaining the force acting on each particle, which is difficult to obtain on a similar scale with physical experimentation [57]. Since it is a Lagrangian method, Newton's second law is applied for each particle in the simulation domain. This explicitly determines the trajectories and kinematics of each particle at every time step by accounting for the interaction between particles and their environment with contact or field forces.

Using Newton's second law, the equations of motion for the translational and rotational motion of each particle, $i$, in contact with a particle or wall, $j$, are as follows: 


$$
\begin{aligned}
& m_{i} \frac{d \mathbf{v}_{i}}{d t}=m_{i} \mathbf{g}+\sum_{j=1}^{N} \mathbf{F}_{i j}, \\
& I_{i} \frac{d \mathbf{w}_{i}}{d t}=\sum_{j=1}^{N} \mathbf{T}_{i j},
\end{aligned}
$$

where $m_{i}$ is the particle mass, $\mathbf{v}_{i}$ is its velocity, $\mathbf{g}$ is the gravitational acceleration, $\mathbf{F}_{i j}$ is the contact force exerted by particle $j$ on $i, \mathbf{I}_{i}$ is the particle inertia, $\boldsymbol{\omega}_{i}$ is its angular velocity, and $\mathbf{T}_{i j}$ is the contact moment.

By assuming that the particles are rigid, spherical, and of uniform material, the contact force, $\mathbf{F}_{i j}$, for particleparticle and particle-wall interactions can be calculated with the Hertz-Mindlin contact model [56]. This force is composed of an elastic and viscous component and is expressed by equations (9a)-(9c) in the normal and tangential directions, being $\widehat{\mathbf{e}}_{\mathrm{n}}$ and $\widehat{\mathbf{e}}_{\mathrm{t}}$ the respective unit vectors. The tangential overlap is truncated to fulfil Coulomb friction criterion in tangential force. Overlap distance $\boldsymbol{\delta}_{i j}$ is composed of a normal and tangential component, as shown in equation (9d). The choice of a contact model depends primarily on the experimental comparison and type of results expected. A simple model, such as the Hooke linear model, can also produce good agreement in some situation [58].

$$
\begin{aligned}
\mathbf{F}_{i j} & =F_{\mathrm{n}, i j} \widehat{\mathbf{e}}_{\mathrm{n}}+F_{\mathrm{t}, i j} \widehat{\mathbf{e}}_{\mathrm{t}}, \\
F_{\mathrm{n}, i j} & =K_{\mathrm{n}} \delta_{\mathrm{n}, i j}-C_{\mathrm{n}} \dot{\delta}_{\mathrm{n}, i j}, \\
F_{\mathrm{t}, i j} & =\min \left(\mu_{i j} F_{\mathrm{n}, i j}, K_{\mathrm{t}} \delta_{\mathrm{t}, i j}-C_{\mathrm{t}} \dot{\delta}_{\mathrm{t}, i j}\right), \\
\boldsymbol{\delta}_{i j} & =\delta_{\mathrm{n}, i j} \widehat{\mathbf{e}}_{\mathrm{n}}+\delta_{\mathrm{t}, i j} \widehat{\mathbf{e}}_{\mathrm{t}} .
\end{aligned}
$$

A constant directional torque (CDT) model is used to calculate the rolling resistance $[59,60]$. A constant moment, $T_{\mathrm{r}, i}$, is applied to a particle to represent the rolling friction, where $\omega_{i}$ and $\omega_{j}$ are the angular velocities of the particles in contact, $\mu_{\mathrm{r}}$ is the rolling friction coefficient, $\bar{r}_{i j}$ is the effective radius, and $F_{n, i j}$ is the contact normal force. The torque is always in the opposite direction to the relative rotation between the two contact particles.

$$
T_{\mathrm{r}, i}=-\frac{\omega_{i}-\omega_{j}}{\left|\omega_{i}-\omega_{j}\right|} \mu_{\mathrm{r}, i j} \bar{r}_{i j} F_{\mathrm{n}, i j} .
$$

Figure 3 shows the schematic of the contact model and rolling resistance model, illustrating two particles, $i$ and $j$, with an overlap, $\boldsymbol{\delta}_{i j}$, and with contact stiffness, $K$, and damping, $C$. Each particle is characterized by its Young's modulus, $E_{i}$, mass, $m_{i}$, and radius, $r_{i}$.

Model coefficients for equation (9) are calculated using equations given in the LIGGGHTS manual [61]. These coefficients depend on the material parameters, such as the restitution coefficient, $e$, Young's modulus, $E$, and Poisson coefficient, $v$.

To numerically solve the motion equations for each particle, the simulation is divided into time steps, $\Delta t$, and the

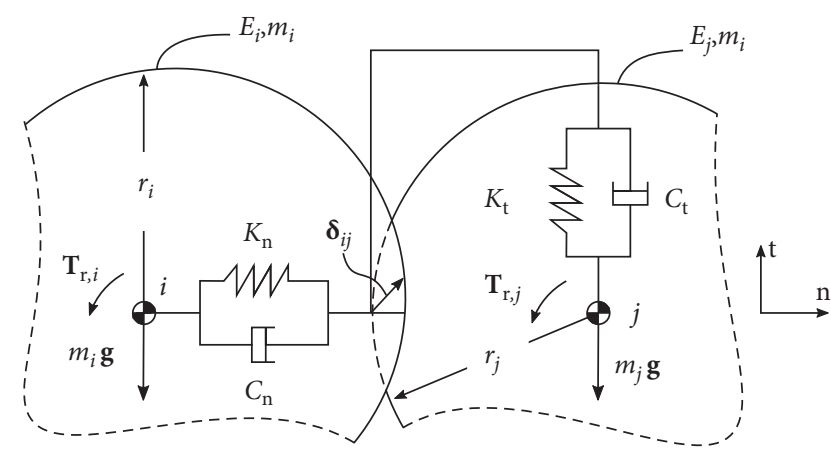

FIgure 3: Contact model.

equations are solved to obtain a solution at the end of each time step. The velocity Verlet algorithm is used for these calculations, which can be derived by an approximation of the Taylor series [62].

DEM simulations are implemented in LIGGGHTS [63], an open source software based on LAMMPS used to perform massive granular simulation in parallel using MPI [64]. This software makes it possible to import CAD files for the wall geometries; assign different movements to these geometries, such as a $3 \mathrm{D}$ vibration with a different amplitude, frequency, and phase; use nonspherical particles [65]; perform stress and wear analysis [8]; and develop smoothed particle hydrodynamics (SHP) models [66] and CFD-DEM coupling simulations [67]. For these reasons, it has been used in the literature for vibrating screen DEM simulations $[8,10]$. LIGGGHTS 3.6.0 was used to perform the simulations on a desktop computer.

\section{Vibrating Screen Simulation}

The simulations in this study make use of data obtained from a vibrating screen in use at a copper mine [3]. This screen is a double-deck linear motion vibrating screen with a size of $3.66 \times 7.32 \mathrm{~m}$ and a $10.5 \mathrm{~mm}$ nominal stroke. The CAD model of this vibrating screen is shown in Figure 4(a), where the upper and lower screen decks, feed chute, and lateral and rear walls that serve as boundaries of the particles are detailed. The lateral wall on the left side is not presented in this figure, but it is included in the simulation. Only the features necessary for DEM are geometrically modeled, as the details of the structure of the machine are not relevant; the screen decks are correctly modeled.

The screen deck is composed of 27 square modules in the longitudinal direction, with a side length of each square module of $305 \mathrm{~mm}$. Each deck has rectangular openings, slotted with the flow direction, of $60 \times 20 \mathrm{~mm}$ (Figure $4(\mathrm{~b})$ ) and $47 \times 11 \mathrm{~mm}$ (Figure 4(c)) for the upper and lower decks, respectively. The opening area represents $30 \%$ and 36 of the upper and lower decks, respectively.

To reduce the computational cost of the DEM simulation, the simulated vibrating screen is a $1 / 12$ th scale model in the cross direction [44] of the real machine, using the symmetry in the $x y$-plane corresponding to a row of modules, as shown in Figure 4. This simplification implies that the intensive variables, 


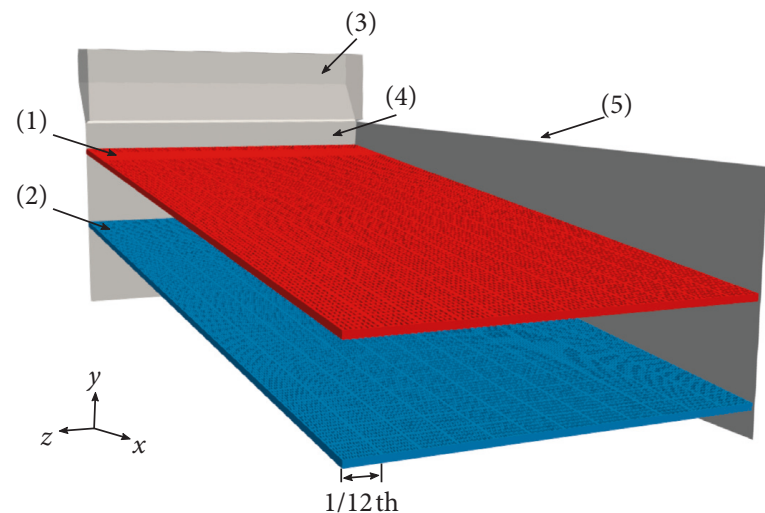

(a)

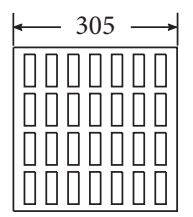

(b)

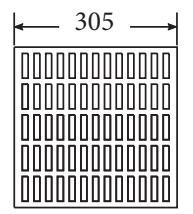

(c)

Figure 4: Geometry of the vibrating screen (a) CAD model showing the (1) upper deck, (2) lower deck, (3) feed chute, (4) rear wall, (5) lateral wall; (b) upper screen deck module; (c) lower screen deck module.

such as force, mass, and inertia, must be multiplied by 12 . In spite of the influence of the particle shape on stratification and passing [46], spherical particles are adopted because of their lower computational cost. The particle size distribution corresponds to nominal data provided by the manufacturer, and a diameter threshold of $6 \mathrm{~mm}$ is used in order to reduce the simulation time [68]. Young's modulus is $E_{\mathrm{p}}=2.3 \cdot 10^{7} \mathrm{~Pa}$ for the particles, and $E_{\text {wall }}=5 \cdot 10^{5} \mathrm{~Pa}$ for the boundary walls. The common simplification to reduce $E[10]$ is not applied because it influences the contact force [69], and thus, the force between the particles and decks. With the period of vibration, $T$, and $N=2^{15}$ steps per cycle, a time step is $\Delta t=T / N$, or approximately $2 \cdot 10^{-6} \mathrm{~s}$. That time step is acceptable for this simulation [63] because it is smaller than the Rayleigh time step. Details of the geometrical conditions and material parameters are listed in Table 1 and are based on nominal data and previous studies $[17,37,46]$. These parameters correspond to the simplified vibrating screen, and thus, the mass flow and width are $1 / 12$ th the real value. The subscript $\mathrm{p}$ refers to the particle.

To promote stratification and provide movement to the ore, a vibrating screen vibrates with a particular frequency, direction, and amplitude. In the DEM simulations, motion is imposed on both decks, with vibration in the $x$-axis and $y$-axis, as well as angularly an amount $\theta$ with respect to its center of mass. The vibration direction is ensured by the phase difference between the vibrations in $x$ and $y$. The vibrational parameters are listed in Table 2 . These parameters are obtained from dynamical simulations, and thus the frequency, $f$, of the deck vibration movement is the same as that in the dynamic simulations. To the comparison of the cases be valid, both cases consider the same value of $M_{\text {ore }}$.

Table 3 lists the parameters used in the dynamical simulations for Cases 1 and 2 that correspond to the nominal data without load and geometrical conditions. The excitation frequency is calculated by $\Omega=2 \pi f$.

For Case 1, the DEM data, parameters for the empty vibrating screen, and equations (1) and (2) are used to obtain the parameters listed in Table 4.
TABLE 1: Parameters used for the DEM simulations.

\begin{tabular}{|c|c|c|c|}
\hline Screen width, $w(\mathrm{~mm})$ & \multicolumn{3}{|c|}{305} \\
\hline Screen length, $l(\mathrm{~m})$ & \multicolumn{3}{|c|}{8.235} \\
\hline Deck thickness, $t(\mathrm{~mm})$ & \multicolumn{3}{|c|}{65} \\
\hline Mass flow, $\dot{M}_{\text {ore }}($ ton $/ \mathrm{h})$ & \multicolumn{3}{|c|}{78.231} \\
\hline Number of particles & \multicolumn{3}{|c|}{42000} \\
\hline Particle shape & \multicolumn{3}{|c|}{ Spherical } \\
\hline \multirow{2}{*}{ Particle diameter, $\phi_{i}(\mathrm{~mm})$} & 76 & 45 & 21 \\
\hline & 19 & 12 & 10 \\
\hline Cumulative particle size distribution, $\Phi_{i}(\%)$ & 100 & 88.84 & 53.85 \\
\hline Density, $\rho_{\text {, }} \rho_{\text {wall }}\left(\mathrm{kg} / \mathrm{m}^{3}\right)$ & \multicolumn{3}{|c|}{$2700 ; 7800$} \\
\hline Young's modulus, $E_{\mathrm{p}} ; E_{\text {wall }}(\mathrm{Pa})$ & \multicolumn{3}{|c|}{$2.3 \cdot 10^{7} ; 5 \cdot 10^{5}$} \\
\hline Poisson coefficient, $v$ & \multicolumn{3}{|c|}{0.3} \\
\hline Restitution coefficient, $e_{\mathrm{p}, \mathrm{p}} ; e_{\mathrm{p}, \text { wall }}$ & \multicolumn{3}{|c|}{$0.1 ; 0.2$} \\
\hline Friction coefficient, $\mu_{\mathrm{p}, \mathrm{p}} ; \mu_{\mathrm{p} \text {,wall }}$ & \multicolumn{3}{|c|}{$0.5 ; 0.545$} \\
\hline Rolling friction coefficient, $\mu_{\mathrm{r}}$ & \multicolumn{3}{|c|}{0.01} \\
\hline Gravity acceleration, $g\left(\mathrm{~m} / \mathrm{s}^{2}\right)$ & \multicolumn{3}{|c|}{9.81} \\
\hline
\end{tabular}

TABLE 2: Vibrational parameters used for DEM simulation.

\begin{tabular}{lc}
\hline Horizontal amplitude, $X_{0}(\mathrm{~mm})$ & 7.5732 \\
Vertical amplitude, $Y_{0}(\mathrm{~mm})$ & 6.5003 \\
Angular amplitude, $\Theta_{0}(\mathrm{rad})$ & $1.488 \cdot 10^{-4}$ \\
Horizontal phase, $\varphi_{x}\left(^{\circ}\right)$ & 92.0178 \\
Vertical phase, $\varphi_{y}\left(^{\circ}\right)$ & 90 \\
Angular phase, $\varphi_{\theta}\left({ }^{\circ}\right)$ & 89.1034 \\
Horizontal position of $\mathrm{cm}, x_{\mathrm{cm}}(\mathrm{m})$ & 4.942 \\
Vertical position of $\mathrm{cm}, y_{\mathrm{cm}}(\mathrm{m})$ & 1.463 \\
Perpendicular position of $\mathrm{cm}, z_{\mathrm{cm}}(\mathrm{m})$ & 0 \\
\hline
\end{tabular}

\section{Results}

5.1. DEM. DEM simulation results are available in [70].

Figure 5 presents snapshots of the DEM simulation of the vibrating screen in the steady state. The ore entering through the chute, distribution on the decks, stratification, and passing can be observed. In this figure, the red spheres have a larger diameter and the blue spheres have smaller diameters. The steady state is defined as when the ore mass on the vibrating screen remains approximately constant with time. 
TABLE 3: Parameters of empty vibrating screen used for the dynamical simulations.

\begin{tabular}{lc}
\hline Force amplitude, $F(\mathrm{~N})$ & 1322071 \\
Frequency, $f(\mathrm{~Hz})$ & 15.75 \\
Force direction, $\alpha\left(^{\circ}\right)$ & 135 \\
Slope, $\beta\left(^{\circ}\right)$ & 5 \\
Horizontal stiffness, $K_{a x}, K_{b x}(\mathrm{~N} / \mathrm{m})$ & 2064000 \\
Vertical stiffness, $K_{a y}, K_{b y}(\mathrm{~N} / \mathrm{m})$ & 4992000 \\
Horizontal damping, $C_{a x}, C_{b x}(\mathrm{Ns} / \mathrm{m})$ & 100000 \\
Vertical damping, $C_{a y}, C_{b y}(\mathrm{Ns} / \mathrm{m})$ & 50000 \\
Mass of empty vibrating screen, $M_{\mathrm{em}}(\mathrm{kg})$ & 24468 \\
Inertia of empty vibrating screen, $I_{\mathrm{em}}\left(\mathrm{kg} \mathrm{m}{ }^{2}\right)$ & 622443 \\
Vertical position of center of mass, $h_{\mathrm{em}}(\mathrm{m})$ & 0.298 \\
Horizontal distance of center of mass to point $A, a_{\mathrm{em}}$ & 2.054 \\
(m) & \\
Horizontal distance of center of mass to point $B, b_{\mathrm{em}}$ & 3.896 \\
(m) & 1.372 \\
Moment arm of excitation force, $p_{\mathrm{em}}(\mathrm{m})$ & 1.065 \\
Distance from $B$ to feed zone, $c(\mathrm{~m})$ & 1.220 \\
Distance from $A$ to discharge zone, $d(\mathrm{~m})$ & 0.020 \\
$\begin{array}{l}\text { Distance from center of mass to upper deck, } h_{\mathrm{m}, \mathrm{sup}} \\
\text { (m) }\end{array}$ & \\
Distance from center of mass to lower deck, $h_{\mathrm{m}, \text { inf }}(\mathrm{m})$ & 0.932 \\
Height of lower inferior, $y_{\mathrm{m}, \text { inf }}(\mathrm{m})$ & 0.960 \\
Height of upper deck, $y_{\mathrm{m}, \mathrm{sup}}(\mathrm{m})$ & 1.875 \\
Height of chute, $y_{\mathrm{ch}}(\mathrm{m})$ & 2.255 \\
\hline
\end{tabular}

TABLE 4: Parameters of the ore obtained from DEM are used for dynamical simulations.

\begin{tabular}{lc}
\hline Ore mass, $M_{\text {ore }}(\mathrm{kg})$ & 3524.2 \\
Ore inertia, $I_{\text {ore }}\left(\mathrm{kg} \cdot \mathrm{m}^{2}\right)$ & 20366 \\
Vertical position of ore center of mass, $h_{\text {ore }}(\mathrm{m})$ & -0.1881 \\
Horizontal position of ore center of mass, $a_{\text {ore }}(\mathrm{m})$ & 3.0184 \\
Mass of screen with load, $M(\mathrm{~kg})$ & 27992 \\
Inertia of screen with load, $I\left(\mathrm{~kg} \cdot \mathrm{m}^{2}\right)$ & 64640 \\
Vertical position of cm of screen with load, $h(\mathrm{~m})$ & 0.2368 \\
Horizontal distance from $\mathrm{cm}$ to point $A, a(\mathrm{~m})$ & 2.1754 \\
Horizontal distance from cm to point $B, b(\mathrm{~m})$ & 3.7746 \\
Moment arm of exciter force, $p(\mathrm{~m})$ & 1.2418 \\
\hline
\end{tabular}

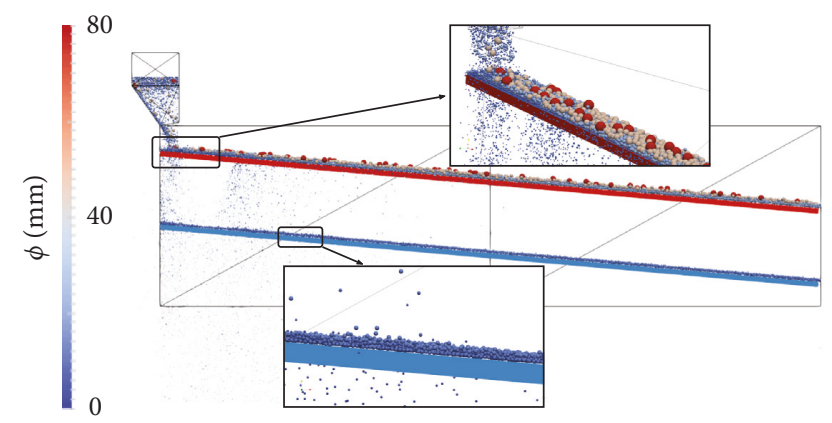

FIGURE 5: DEM simulation in LIGGGHTS software for a doubledeck vibrating screen.

The total force and moment over the screen exerted by the ore are presented in Figure 6 for the $x, y$, and, $\theta$ directions. The vertical component, $F_{y \text {,dem }}$, has a greater amplitude than the horizontal component $F_{x \text { dem }}$, and its peak amplitude is 7 times greater. Both amplitudes match when they have null values, as

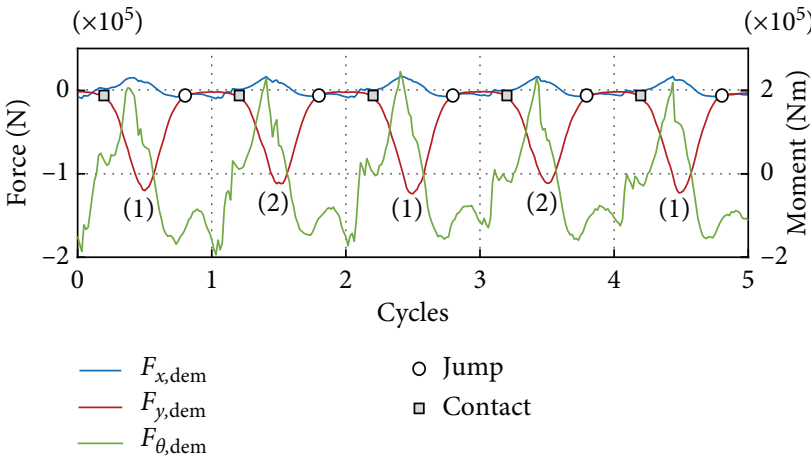

FIGURE 6: DEM force in $x$ and $y$ directions, and DEM moment in $\theta$ direction. Contact and jump points are also presented.

that corresponds to when the ore is detached from the screen. The value of $F_{y \text {,dem }}$ exhibits an amplitude change every cycle, i.e., between peaks (1) and (2), that is related to the ore movement. On average, the first is equal to $122.4 \mathrm{kN}$ and the second is equal to $111.5 \mathrm{kN}$. The moment, $F_{\theta \text {,dem }}$, has the same tendency as components $x$ and $y$, and its maximum amplitude occurs when ore comes into contact with the screen deck.

The overall screening performance of both decks can be investigated with the partition curve of the overflow, which is defined as the ratio of the number of residue particles in the overflow to that of fed particles [44], and is shown in Figure 7. In terms of mass flow, the partition number is equal to

$$
c_{i}=\frac{\dot{m}_{\mathrm{o}}}{\dot{m}_{\mathrm{f}}}
$$

for each $i$ particle size, where o refers to overflow stream and $\mathrm{f}$ to feed. These results agree with the nominal screening efficiency of the vibrating screen, which is approximately $90 \%$.

5.2. Comparison of Case 1 and Case 2. The results for Case 1 are compared with those of Case 2 , and the force exerted by the ore on the vibrating screens and movement of the machine in its supports are analyzed.

5.2.1. Inertia Force and DEM Force. Figure 8 compares the forces in Case 1 and Case 2 with a frequency spectrum and orbit. Figure 8(a) shows the frequency spectrum of the signal in the vertical direction, $y$. For Case 1 , only the $1 \mathrm{X}$ component is observed. For Case 2, a constant component at $0 \mathrm{~Hz}$ is observed, which represents the mean time value, along with harmonics from $1 \mathrm{X}-4 \mathrm{X}$. The logarithmic spectrum shown in Figure 8(c) exhibits, in addition to these harmonics, nonsynchronous components at $0.5 \mathrm{X}$ and $1.5 \mathrm{X}$, which are highlighted in the grass spectrum.

Figure $8(\mathrm{~b})$ shows both forces in the $x y$-plane, allowing for a graphical understanding of the direction of each force. In Case 1, the orbit is elliptical with a nearly negligible semiminor axis, and thus, it approximately corresponds to a line. Case 2 has an ore force that is always negative in the direction of $y$ because the ore cannot produce an adhesion force that lifts up the screen decks. 


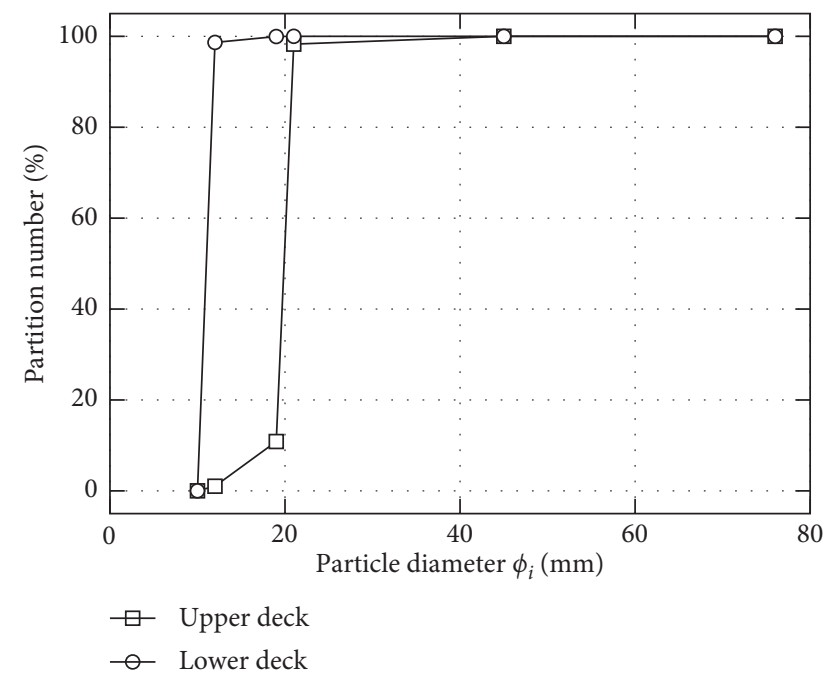

Figure 7: Partition curves of the overflow for the upper and lower decks.

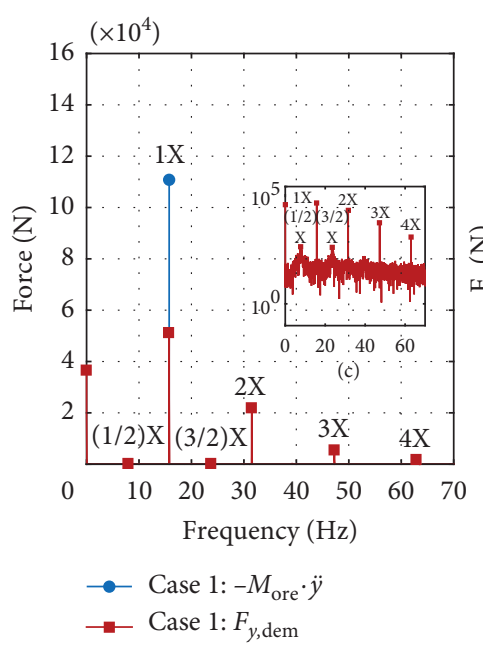

(a)

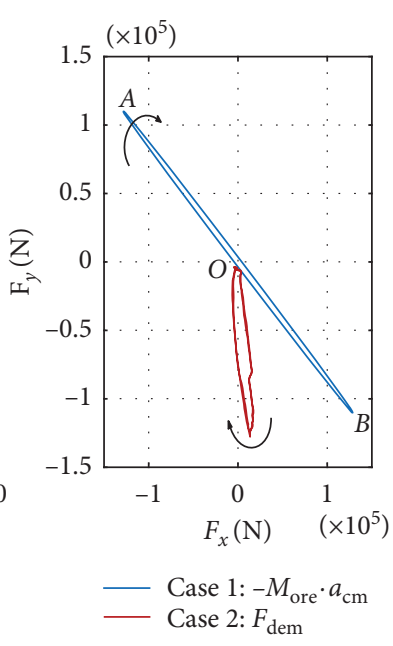

(b)
FIGURE 8: Force comparison: (a) frequency spectrum in $y$, (b) orbit, and (c) logarithmic spectrum of $F_{y, \text { dem }}$.

Arrows indicate the variation in each force over time. In Case 2, the orbit is a cycle, from $O$ to $O$ in clockwise direction, whereas the orbit of Case 1 moves between $A$ and $B$. While the Case 1 orbit moves from $B$ to $A$, the Case 2 orbit stays close to zero.

In analyzing these results, it can be concluded that Case 1 does not accurately physically represent the effect of the ore on the vibrating screen, because this force must be vertical and repulsive, as in the DEM simulation.

5.2.2. Supports Movement. Movement in the two cases is compared by means of orbit analysis of the movement of support $A$. Figure 9 presents the frequency spectrum and displacement orbit for support $A$. Figure 9(a) shows the frequency spectrum of vertical movement and indicates that Case 1 only exhibits a $1 \mathrm{X}$ component, which differs by $12 \%$

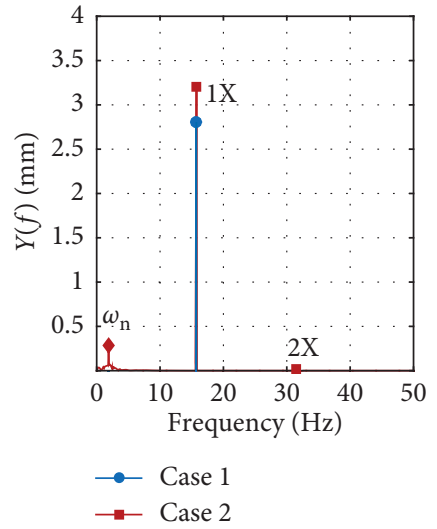

(a)

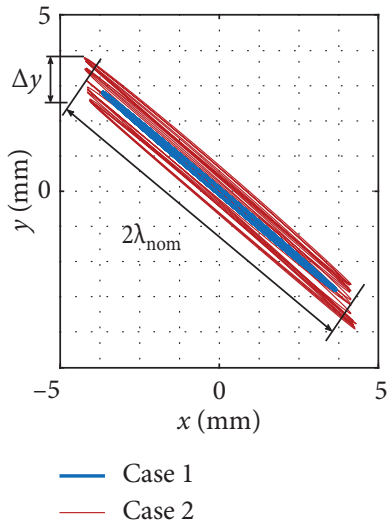

(b)
FIgUre 9: Comparison of the movement of support $A$ in cases 1 and 2: (a) frequency spectrum and (b) orbit.

from that of Case 2. Case 2 exhibits a low amplitude harmonic at $2 \mathrm{X}$. For Case 2, owing to the transient condition of $\mathbf{F}_{\text {dem }}$, a resonant zone appears near $1.875 \mathrm{~Hz}$. This corresponds closely to the values of the natural frequencies, $\omega_{\mathrm{nt}, \theta}$ and $\omega_{\mathrm{nt}, x}$, which are $1.982 \mathrm{~Hz}$ and $2.067 \mathrm{~Hz}$, respectively.

Figure 9(b) shows the orbits. In Case 1, an elliptical orbit is clearly observed, while in Case 2, the transient condition of the excitation force, $\mathbf{F}_{\mathrm{dem}}$, results in an elliptical trajectory that changes position in the vertical direction by an amount $\Delta y=1.2 \mathrm{~mm}$. A difference in stroke $2 \lambda_{i}$ is also observed, equal to $2 \lambda_{1}=9.230 \mathrm{~mm}$ in Case 1 and $2 \lambda_{2}=10.592 \mathrm{~mm}$ in case 2 on average. These values agree with commonly found in experimental measurements and in the literature $[3,10]$. Furthermore, Figure 9(b) presents the nominal stroke length equal to $2 \lambda_{\text {nom }}=10.5 \mathrm{~mm}$. Comparing nominal stroke with simulated stroke, case 2 provides a better agreement.

5.2.3. Angular Displacement. Angular displacement of the vibrating screen is obtained, and it is presented in Figure 10. Both cases present a low peak amplitude, less than $0.025^{\circ}$. Figure 10(a) presents frequency spectrum showing that both have a $1 \mathrm{X}$ component that differs on $0.003^{\circ}$. Case 2 presents a low amplitude $2 \mathrm{X}$ component and, as well as vertical movement, a resonant zone. Figure 10(b) shows waveform of angular displacement. It should be noted that Case 2 has nonzero mean value equal to $\bar{\theta}_{2}$. This value depends of $F_{\theta \text {,dem }}$, which is calculated based on $F_{x \text {,dem }}$ and $F_{y \text {,dem }}$ and the position of the center of mass of the ore with respect to the center of mass of vibrating screen.

\section{Discussion and Conclusion}

Conclusions obtained in this study can be summarized as follows:

(i) The proposed dynamic model allows for prediction of the behavior of the vibrating screen operating at both the nominal condition and high angular displacement with a nonlinear model [3]. This model simulated ore movement along with the screen deck 


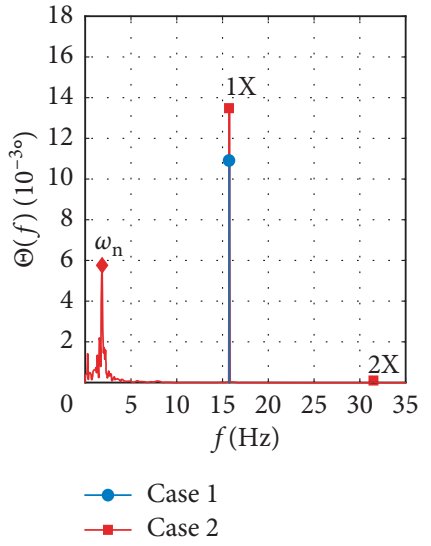

(a)

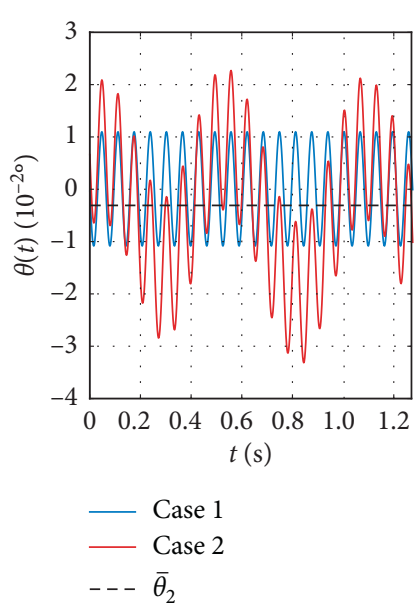

(b)

Figure 10: Comparison of the angular displacement of vibrating screen: (a) frequency spectrum and (b) waveform.

(Case 1), as well as the ore force over the screen decks calculated with DEM (Case 2). In both cases, the movement of the vibrating screen supports was also obtained.

(ii) DEM simulation of a double-deck vibrating screen was carried out using the open-source LIGGGHTS software. Movement of the ore center of mass and the force exerted by the ore over the screen deck were obtained. The $\mathbf{F}_{\mathrm{dem}}$ force has the same frequency as the excitation force; high oscillations in the ore do not produce significant changes in the force exerted over the screen.

(iii) The partition curve and stroke of the vibrating screen motion have very good agreement with the nominal data, validating the model results.

(iv) In a comparison of the results for the proposed cases, where the ore is represented as moving together with the vibrating screen (Case 1), or the ore force is obtained from DEM (Case 2), it is observed that:

(a) The force over the screen deck is completely different in both cases, both in terms of the magnitude (the peak-to-peak amplitude in Case 1 is more than twice that of Case 2) and the shape on the $x y$-plane. Case 1 produces an unrealistic force, because it includes a contact force of adhesion between the ore and screen deck. However, this is the hypothesis used in most of the existing dynamic models available in the literature. The DEM model allows calculation of a force closer to reality, because it calculates the interaction of each individual particle with the screen deck.

(b) Case 1 available in the literature was successfully implemented. The computation of Case 1 is faster than Case 2, because only a linear ordinary differential of three-degrees-of-freedom equation is solved, in contrast to DEM simulation that simulates the movement of 42000 particles. This is the reason why Case 1 is commonly used in the mining industry.

(c) Case 2 is a new simulation approach that allows the coupling of simulation results in DEM in dynamic models. This model is able to evaluate how the ore affects the movement of the vibrating screen.

(d) Notwithstanding the clear inequality in the force calculated for cases 1 and 2, the approach used in Case 1 can be used to predict the movement of vibrating screen if a correct calibration parameter is included.

(e) Comparing with the nominal data and the results of Case 2, frequency, direction, and inclination calculated with Case 1 are accurate. The amplitude obtained using Case 1 is not accurate and must be corrected. In this case, the parameter of mass of ore $M_{\text {ore }}$ must be adjusted with experimental data, decreasing its value so that the amplitude increases. To decrease the value of $M_{\text {ore }}$ is physically correct, since the model of Case 1 considers that all the ore is in contact with the screen decks, while there is ore in free fall that is not in contact.

(v) Under nominal operating conditions, the angular response, $\theta(t)$, has low amplitude $\left(0.014^{\circ}\right)$, whereas the steady responses obtained for the linear model, equations (5)-(7), and the nonlinear model, equations (12)-(14), have negligible differences. Consequently, for simplification and lower computational cost, the linear model can be used for the steady case or without deterioration in the supports. For transient signals or when the amplitude of the angular response is high, the linear model is not recommended.

(vi) The proposed dynamic model allows for greater accuracy and validity in different operating conditions, which is useful for predicting the angle of operation and the vibratory amplitude, parameters that affect the screening efficiency. 


\section{Appendix}

\section{Nonlinear Equations of Motion}

$$
\begin{aligned}
M \ddot{x} & +\dot{x}\left(C_{a x}+C_{b x}\right)+\dot{\theta} \sin \theta\left[C_{a x}(a \cos \beta-h \sin \beta)+C_{b x}(-h \sin \beta-b \cos \beta)\right] \\
& +\dot{\theta} \cos \theta\left[C_{a x}(a \sin \beta+h \cos \beta)+C_{b x}(h \sin \beta+b \cos \beta)\right]+x\left(K_{a x}+K_{b x}\right) \\
& +\sin \theta\left[K_{a x}(h \cos \beta+a \sin \beta)+K_{b x}(h \cos \beta-b \sin \beta)\right]+\cos \theta\left[K_{a x}(h \sin \beta-a \cos \beta)+K_{b x}(h \sin \beta+b \cos \beta)\right] \\
& +K_{a x}(a \cos \beta-h \sin \beta)+K_{b x}(-h \sin \beta-b \cos \beta)=F \sin (\Omega t) \cos (\theta+\alpha+\beta)+F_{x, \mathrm{dem}}(t), \\
M \ddot{y} & +\dot{y}\left(C_{a y}+C_{b y}\right)+\dot{\theta} \sin \theta\left[C_{a y}(-h \cos \beta+a \sin \beta)+C_{b y}(h \cos \beta-b \sin \beta)\right] \\
& +\dot{\theta} \cos \theta\left[C_{a y}(h \sin \beta-a \cos \beta)+C_{b y}(h \sin \beta+b \cos \beta)\right]+y\left(K_{a y}+K_{b y}\right) \\
& -\sin \theta\left[K_{a y}(h \cos \beta-a \sin \beta)+K_{b y}(-h \cos \beta+b \sin \beta)\right]+\cos \theta\left[K_{a y}(h \sin \beta-a \cos \beta)+K_{b y}(h \sin \beta+b \cos \beta)\right] \\
& +K_{a y}(h \cos \beta+a \sin \beta)+K_{b y}(h \cos \beta-b \sin \beta)=F \sin (\Omega t) \sin (\theta+\alpha+\beta)+F_{y, \text { dem }}(t),
\end{aligned}
$$

$\ddot{I \theta}+\dot{\theta} \sin \theta \cos \theta\left[2 C_{a y}(h \sin \beta-a \cos \beta)(h \cos \beta+a \sin \beta)+2 C_{b y}(h \sin \beta+b \cos \beta)(h \cos \beta-b \sin \beta)\right.$

$\left.+2 C_{a x}(h \cos \beta+a \sin \beta)(-h \sin \beta+a \cos \beta)+2 C_{b x}(-h \cos \beta+b \sin \beta)(h \sin \beta+b \cos \beta)\right]$

$+\dot{\theta} \cos ^{2} \theta\left[C_{a y}(h \sin \beta-a \cos \beta)^{2}+C_{b y}(h \sin \beta+b \cos \beta)^{2}+C_{a x}(h \cos \beta+a \sin \beta)^{2}+C_{b x}(h \cos \beta-b \sin \beta)^{2}\right]$

$+\dot{\theta} \sin ^{2} \theta\left[C_{a y}(h \cos \beta+a \sin \beta)^{2}+C_{b y}(-h \cos \beta+b \sin \beta)^{2}+C_{a x}(h \sin \beta-a \cos \beta)^{2}+C_{b x}(h \sin \beta+b \cos \beta)^{2}\right]$

$+\dot{x} \cos \theta\left[C_{a x}(h \cos \beta+a \sin \beta)+C_{b x}(h \cos \beta-b \sin \beta)\right]+\dot{x} \sin \theta\left[C_{a x}(-h \sin \beta+a \cos \beta)-C_{b x}(h \sin \beta+b \cos \beta)\right]$

$+\dot{y} \cos \theta\left[C_{a y}(h \sin \beta-a \cos \beta)+C_{b y}(h \sin \beta+b \cos \beta)\right]+\dot{y} \sin \theta\left[C_{a y}(h \cos \beta+a \sin \beta)+C_{b y}(h \cos \beta-b \sin \beta)\right]$

$+x \cos \theta\left[K_{a x}(a \sin \beta+h \cos \beta)+K_{b x}(-b \sin \beta+h \cos \beta)\right]+x \sin \theta\left[K_{a x}(a \cos \beta-h \sin \beta)-K_{b x}(b \cos \beta+h \sin \beta)\right]$

$+y \cos \theta\left[K_{a y}(-a \cos \beta+h \sin \beta)+K_{b y}(b \cos \beta+h \sin \beta)\right]+y \sin \theta\left[K_{a y}(a \sin \beta+h \cos \beta)+K_{b y}(-b \sin \beta+h \cos \beta)\right]$

$+\cos 2 \theta\left\{K_{a x}\left[a h\left(-\cos ^{2} \beta+\sin ^{2} \beta\right)+\left(h^{2}-a^{2}\right) \sin \beta \cos \beta\right]+K_{a y}\left[a h\left(\cos ^{2} \beta-\sin ^{2} \beta\right)+\left(-h^{2}+a^{2}\right) \sin \beta \cos \beta\right]\right.$

$\left.+K_{b x}\left[b h\left(\cos ^{2} \beta-\sin ^{2} \beta\right)+\left(h^{2}-b^{2}\right) \sin \beta \cos \beta\right]+K_{b y}\left[b h\left(-\cos ^{2} \beta+\sin ^{2} \beta\right)+\left(-h^{2}+b^{2}\right) \sin \beta \cos \beta\right]\right\}$

$+\cos \theta \sin \theta\left\{K_{a x}\left[4 a h \cos \beta \sin \beta+\left(-h^{2}+a^{2}\right) \sin ^{2} \beta+\left(h^{2}-a^{2}\right) \cos ^{2} \beta\right]+K_{a y}\left[4 a h \cos \beta \sin \beta+\left(-h^{2}+a^{2}\right) \sin ^{2} \beta+\left(h^{2}-a^{2}\right) \cos ^{2} \beta\right]\right.$

$\left.-K_{b x}\left[4 b h \cos \beta \sin \beta-\left(-h^{2}+b^{2}\right) \sin ^{2} \beta-\left(h^{2}-b^{2}\right) \cos ^{2} \beta\right]+K_{b y}\left[4 b h \cos \beta \sin \beta-\left(-h^{2}+b^{2}\right) \sin ^{2} \beta-\left(h^{2}-b^{2}\right) \cos ^{2} \beta\right]\right\}$

$+\cos \theta\left\{K_{a x}\left[a h\left(\cos ^{2} \beta-\sin ^{2} \beta\right)+\left(-h^{2}+a^{2}\right) \sin \beta \cos \beta\right]-K_{a y}\left[a h\left(\cos ^{2} \beta-\sin ^{2} \beta\right)+\left(-h^{2}+a^{2}\right) \sin \beta \cos \beta\right]\right.$

$\left.-K_{b x}\left[b h\left(\cos ^{2} \beta-\sin ^{2} \beta\right)+\left(h^{2}-b^{2}\right) \sin \beta \cos \beta\right]+K_{b y}\left[b h\left(\cos ^{2} \beta-\sin ^{2} \beta\right)+\left(h^{2}-b^{2}\right) \sin \beta \cos \beta\right]\right\}$

$+\sin \theta\left[K_{a x}(a \cos \beta-h \sin \beta)^{2}+K_{a y}(a \sin \beta+h \cos \beta)^{2}+K_{b x}(h \sin \beta+b \cos \beta)^{2}+K_{b y}(h \cos \beta-b \sin \beta)^{2}\right]$

$=-F \sin (\Omega t) p \cos \alpha+F_{\theta, \text { dem }}(t)$.

\section{Data Availability}

The DEM raw data used to support the findings of this study have been deposited in the "Raw data of DEM simulation of linear motion double deck vibrating screen" repository (DOI: 10.17632/cc798dvdbn.2).

\section{Conflicts of Interest}

The authors declare that they have no conflicts of interest.

\section{Acknowledgments}

This work was supported by CONICYT/PCHA/Magíster/ Nacional 2016-22162452.

\section{References}

[1] L. Zhao, Y. Zhao, C. Bao, Q. Hou, and A. Yu, "Optimisation of a circularly vibrating screen based on DEM simulation and Taguchi orthogonal experimental design," Powder Technology, vol. 310, pp. 307-317, 2017.

[2] A. Noble and G. H. Luttrell, "A review of state-of-the-art processing operations in coal preparation," International Journal of Mining Science and Technology, vol. 25, no. 4, pp. 511-521, 2015.

[3] C. G. Rodríguez, M. A. Moncada, E. E. Dufeu, and M. I. Razeto, "Nonlinear model of vibrating screen to determine permissible spring deterioration for proper separation," Shock and Vibration, vol. 2016, Article ID 4028583, 7 pages, 2016. 
[4] N. Standish, A. K. Bharadwaj, and G. Hariri-Akbari, "A study of the effect of operating variables on the efficiency of a vibrating screen," Powder Technology, vol. 48, no. 2, pp. 161-172, 1986.

[5] B. Ramatsetse, K. Mpofu, and O. Makinde, "Failure and sensitivity analysis of a reconfigurable vibrating screen using finite element analysis," Case Studies in Engineering Failure Analysis, vol. 9, pp. 40-51, 2017.

[6] O. A. Makinde, B. I. Ramatsetse, and K. Mpofu, "Review of vibrating screen development trends: linking the past and the future in mining machinery industries," International Journal of Mineral Processing, vol. 145, pp. 17-22, 2015.

[7] G. Asbjörnsson, M. Bengtsson, E. Hulthén, and M. Evertsson, "Modelling of discrete downtime in continuous crushing operation," Minerals Engineering, vol. 98, pp. 22-29, 2016.

[8] A. Jafari and V. S. Nezhad, "Employing DEM to study the impact of different parameters on the screening efficiency and mesh wear," Powder Technology, vol. 297, pp. 126-143, 2016.

[9] L. Zhao, Y. Zhao, C. Liu, J. Li, and H. Dong, "Simulation of the screening process on a circularly vibrating screen using 3DDEM," Mining Science and Technology, vol. 21, no. 5, pp. 677-680, 2011.

[10] M. Jahani, A. Farzanegan, and M. Noaparast, "Investigation of screening performance of banana screens using LIGGGHTS DEM solver," Powder Technology, vol. 283, pp. 32-47, 2015.

[11] A. Mular, "Size separation," in Principles of Mineral Processing, M. C. Fuerstenau and K. N. Han, Eds., p. 54, Society for Mining, Metallurgy, and Exploration (SME), Littleton, CO, USA, 2003.

[12] G. K. N. S. Subasinghe, W. Schaap, and E. G. Kelly, "Modelling the screening process-an empirical approach," Minerals Engineering, vol. 2, no. 2, pp. 235-244, 1989.

[13] A. Kim, M. Doudkin, A. Vavilov, and G. Guryanov, "New vibroscreen with additional feed elements," Archives of Civil and Mechanical Engineering, vol. 17, no. 4, pp. 786-794, 2017.

[14] M. Soldinger, "Interrelation of stratification and passage in the screening process," Minerals Engineering, vol. 12, no. 5, pp. 497-516, 1999.

[15] D. I. Stoicovici, M. Ungureanu, N. Ungureanu, and M. Banica, "Computer model for sieves' vibrations analysis, using an algorithm based on the false-position method," American Journal of Applied Sciences, vol. 6, no. 1, pp. 48-56, 2009.

[16] H. Li and Y. Li, "Simulation and analysis of nonlinear motion for material particles on vibrating screen," in Proceedings of 2011 International Conference on New Technology of Agricultural, vol. 1, pp. 38-43, IEEE, Zibo, China, May 2011.

[17] J. Xiao and X. Tong, "Characteristics and efficiency of a new vibrating screen with a swing trace," Particuology, vol. 11, no. 5, pp. 601-606, 2013.

[18] L. Zhao, C. Liu, and J. Yan, "A virtual experiment showing single particle motion on a linearly vibrating screen-deck," Mining Science and Technology, vol. 20, no. 2, pp. 276-280, 2010.

[19] L. Wang, Z. Ding, S. Meng, H. Zhao, and H. Song, "Kinematics and dynamics of a particle on a non-simple harmonic vibrating screen," Particuology, vol. 32, pp. 167-177, 2017.

[20] L. Katarzyna, M. Remigiusz, and W. Piotr, "Mathematical and empirical description of screen blocking," Granular Matter, vol. 18, p. 13, 2016.

[21] Z. Yue-min, L. Chu-sheng, H. Xiao-mei, Z. Cheng-yong, W. Yi-bin, and R. Zi-ting, "Dynamic design theory and application of large vibrating screen," Procedia Earth and Planetary Science, vol. 1, no. 1, pp. 776-784, 2009.
[22] S. Baragetti and F. Villa, "A dynamic optimization theoretical method for heavy loaded vibrating screens," Nonlinear Dynamics, vol. 78, no. 1, pp. 609-627, 2014.

[23] S. Wolny, T. Banaszewski, S. Dzik, and F. Matachowski, "Evaluation of the state of stress in structural components of a screen separator," Mechanics and Control, vol. 29, no. 2, pp. 88-97, 2010.

[24] C. L. Li, F. He, Y. Y. Zhang, Y. Gao, and P. Gao, "Failure analysis and structure improvement of beam of liner vibrating screen," Advanced Materials Research, vol. 619, pp. 69-73, 2012.

[25] G. Asbjörnsson, E. Hulthén, and M. Evertsson, "Modelling and simulation of dynamic crushing plant behavior with MATLAB/Simulink," Minerals Engineering, vol. 43-44, pp. 112-120, 2013.

[26] F. Elskamp, H. Kruggel-Emden, M. Hennig, and U. Teipel, "Benchmarking of process models for continuous screening based on discrete element simulations," Minerals Engineering, vol. 83, pp. 78-96, 2015.

[27] H. Jiang, Y. Zhao, C. Duan et al., "Dynamic characteristics of an equal-thickness screen with a variable amplitude and screening analysis," Powder Technology, vol. 311, pp. 239-246, 2017.

[28] X.-M. He and C.-S. Liu, "Dynamics and screening characteristics of a vibrating screen with variable elliptical trace," Mining Science and Technology, vol. 19, no. 4, pp. 508-513, 2009.

[29] C. Liu, L. Peng, and F. Li, "Survey of signal processing methods and research on vibrating screen fault diagnosis," in Proceedings of 2011 2nd International Conference on Mechanic Automation and Control Engineering, MACE 2011, pp. 1709-1712, Inner Mongolia, China, July 2011.

[30] C. S. Liu, S. M. Zhang, H. P. Zhou et al., "Dynamic analysis and simulation of four-axis forced synchronizing banana vibrating screen of variable linear trajectory," Journal of Central South University of Technology, vol. 19, no. 6, pp. 1530-1536, 2012.

[31] S. Baragetti, "Innovative structural solution for heavy loaded vibrating screens," Minerals Engineering, vol. 84, pp. 15-26, 2015.

[32] L. I. Slepyan and V. I. Slepyan, "Coupled mode parametric resonance in a vibrating screen model," Mechanical Systems and Signal Processing, vol. 43, no. 1-2, pp. 295-304, 2014.

[33] S. A. Zahedi and V. Babitsky, "Modeling of autoresonant control of a parametrically excited screen machine," Journal of Sound and Vibration, vol. 380, pp. 78-89, 2016.

[34] L.-P. Peng, C.-S. Liu, B.-C. Song, J.-D. Wu, and S. Wang, "Improvement for design of beam structures in large vibrating screen considering bending and random vibration," Journal of Central South University, vol. 22, no. 9, pp. 3380-3388, 2015.

[35] H. Jiang, C. Duan, J. Wu et al., "Kinematics characteristics of the vibrating screen with rigid-flexible screen rod and the behavior ofmoist coal particles during the dry deep screening process," Powder Technology, vol. 319, pp. 92-101, 2017.

[36] M. Moncada and C. G. Rodríguez, "Respuesta de un harnero vibratorio ante la pérdida de rigidez en los apoyos, Ingeniare," Revista Chilena de Ingeniería, vol. 24, pp. 25-31, 2016.

[37] P. W. Cleary, M. D. Sinnott, R. D. Morrison, S. Cummins, and G. W. Delaney, "Analysis of cone crusher performance with changes in material properties and operating conditions using DEM," Minerals Engineering, vol. 100, pp. 49-70, 2017.

[38] N. Weerasekara, M. Powell, P. Cleary et al., "The contribution of DEM to the science of comminution," Powder Technology, vol. 248, pp. 3-24, 2013. 
[39] P. W. Cleary and M. L. Sawley, "DEM modelling of industrial granular flows: 3D case studies and the effect of particle shape on hopper discharge," Applied Mathematical Modelling, vol. 26, no. 2, pp. 89-111, 2002.

[40] A. Refahi, J. A. Mohandesi, and B. Rezai, "Discrete element modeling for predicting breakage behavior and fracture energy of a single particle in a jaw crusher," International Journal of Mineral Processing, vol. 94, no. 1-2, pp. 83-91, 2010.

[41] M. D. Sinnott and P. W. Cleary, "Particulate and water mixing in the feed box for a screen," Minerals Engineering, vol. 109, pp. 109-125, 2017.

[42] P. W. Cleary, M. D. Sinnott, and R. D. Morrison, "Separation performance of double deck banana screens-Part 1: flow and separation for different accelerations," Minerals Engineering, vol. 22, no. 14, pp. 1218-1229, 2009.

[43] P. W. Cleary, M. D. Sinnott, and R. D. Morrison, "Separation performance of double deck banana screens-Part 2: quantitative predictions," Minerals Engineering, vol. 22, no. 14, pp. 1230-1244, 2009.

[44] K. J. Dong, A. B. Yu, and I. Brake, "DEM simulation of particle flow on a multi-deck banana screen," Minerals Engineering, vol. 22, no. 11, pp. 910-920, 2009.

[45] J. W. Fernandez, P. W. Cleary, M. D. Sinnott, and R. D. Morrison, "Using SPH one-way coupled to DEM to model wet industrial banana screens," Minerals Engineering, vol. 24, no. 8, pp. 741-753, 2011.

[46] G. W. Delaney, P. W. Cleary, M. Hilden, and R. D. Morrison, "Testing the validity of the spherical DEM model in simulating real granular screening processes," Chemical Engineering Science, vol. 68, no. 1, pp. 215-226, 2012.

[47] C. Liu, H. Wang, Y. Zhao, L. Zhao, and H. Dong, "DEM simulation of particle flow on a single deck banana screen," International Journal of Mining Science and Technology, vol. 23, no. 2, pp. 273-277, 2013.

[48] H. Dong, C. Liu, Y. Zhao, and L. Zhao, "Influence of vibration mode on the screening process," International Journal of Mining Science and Technology, vol. 23, no. 1, pp. 95-98, 2013.

[49] Z. Li, X. Tong, B. Zhou, and X. Wang, "Modeling and parameter optimization for the design of vibrating screens," Minerals Engineering, vol. 83, pp. 149-155, 2015.

[50] L. Zhao, Y. Zhao, C. Bao, Q. Hou, and A. Yu, "Laboratory-scale validation of a DEM model of screening processes with circular vibration," Powder Technology, vol. 303, pp. 269-277, 2016.

[51] K. Dong, A. H. Esfandiary, and A. Yu, "Discrete particle simulation of particle flow and separation on a vibrating screen: effect of aperture shape," Powder Technology, vol. 314, pp. 195-202, 2016.

[52] A. A. Harzanagh, E. C. Orhan, and S. L. Ergun, "Discrete element modelling of vibrating screens," Minerals Engineering, vol. 121, pp. 107-121, 2018.

[53] Z. Wang, C. Liu, J. Wu, H. Jiang, and Y. Zhao, "Impact of screening coals on screen surface and multi-index optimization for coal cleaning production," Journal of Cleaner Production, vol. 187, pp. 562-575, 2018.

[54] H. Jiang, Y. Zhao, C. Duan et al., "Kinematics of variableamplitude screen and analysis of particle behavior during the process of coal screening," Powder Technology, vol. 306, pp. 88-95, 2017.

[55] L. Peng, Z. Wang, W. Ma, X. Chen, Y. Zhao, and C. Liu, "Dynamic influence of screening coals on a vibrating screen," Fuel, vol. 216, pp. 484-493, 2018.

[56] P. A. Cundall and O. D. L. Strack, "A discrete numerical model for granular assemblies," Géotechnique, vol. 29, no. 1, pp. 47-65, 1979.
[57] H. P. Zhu, Z. Y. Zhou, R. Y. Yang, and A. B. Yu, "Discrete particle simulation of particulate systems: a review of major applications and findings," Chemical Engineering Science, vol. 63, no. 23, pp. 5728-5770, 2008.

[58] A. Di Renzo and F. P. Di Maio, "Comparison of contact-force models for the simulation of collisions in DEM-based granular flow codes," Chemical Engineering Science, vol. 59, no. 3, pp. 525-541, 2004.

[59] Y. Zhou, B. Wright, R. Yang, B. Xu, and A. Yu, "Rolling friction in the dynamic simulation of sandpile formation," Physica A: Statistical Mechanics and its Applications, vol. 269, no. 2-4, pp. 536-553, 1999.

[60] J. Ai, J. F. Chen, J. M. Rotter, and J. Y. Ooi, "Assessment of rolling resistance models in discrete element simulations," Powder Technology, vol. 206, no. 3, pp. 269-282, 2011.

[61] C. Kloss, LIGGGHTS(R)-PUBLIC Documentation, 2016, http://cfdem.com.

[62] H. Kruggel-Emden, M. Sturm, S. Wirtz, and V. Scherer, "Selection of an appropriate time integration scheme for the discrete element method (DEM)," Computers and Chemical Engineering, vol. 32, no. 10, pp. 2263-2279, 2008.

[63] C. Kloss, C. Goniva, G. Aichinger, and S. Pirker, "Comprehensive DEM-DPM-CFD simulations-model synthesis, experimental validation and scalabilit," in Proceedings of Seventh International Conference on CFD in the Minerals and Process Industries, CSIRO, Melbourne, VIC, Australia, December 2009.

[64] R. Berger, C. Kloss, A. Kohlmeyer, and S. Pirker, "Hybrid parallelization of the LIGGGHTS open-source DEM code," Powder Technology, vol. 278, pp. 234-247, 2015.

[65] S. Amberger, M. Friedl, C. Goniva, S. Pirker, and C. Kloss, "Approximation of objects by spheres for multisphere simulations in DEM," in Proceedings of European Congress on Computational Methods in Applied Sciences and Engineering, Vienna, Austria, October 2012.

[66] B. Nassauer, T. Liedke, and M. Kuna, "Development of a coupled discrete element (DEM)-smoothed particle hydrodynamics $(\mathrm{SPH})$ simulation method for polyhedral particles," Computational Particle Mechanics, vol. 3, no. 1, pp. 95-106, 2016.

[67] C. Kloss, C. Goniva, A. Hager, S. Amberger, and S. Pirker, "Models, algorithms and validation for opensource DEM and CFD-DEM," Progress in Computational Fluid Dynamics, An International Journal, vol. 12, no. 2-3, pp. 140-152, 2012.

[68] T. Brosh, H. Kalman, and A. Levy, "Accelerating CFD-DEM simulation of processes with wide particle size distributions," Particuology, vol. 12, pp. 113-121, 2014.

[69] S. Lommen, D. Schott, and G. Lodewijks, "DEM speedup: stiffness effects on behavior of bulk material," Particuology, vol. 12, pp. 107-112, 2014.

[70] M. Moncada, Raw Data of DEM Simulation of Linear Motion Double Deck Vibrating Screen, Dataset on Mendeley, October 2018, https://data.mendeley.com/datasets/cc798dvdbn/2. 


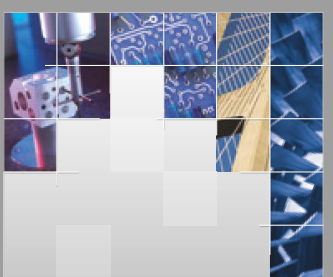

\section{Enfincering}
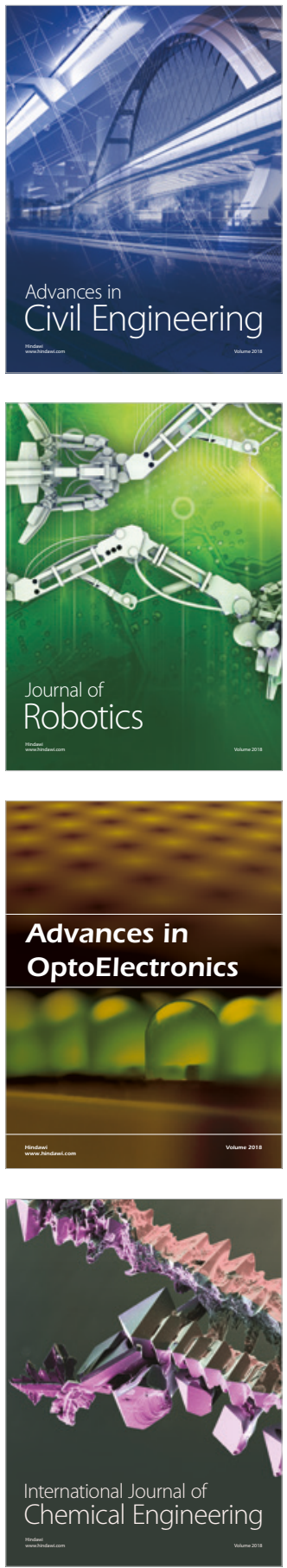

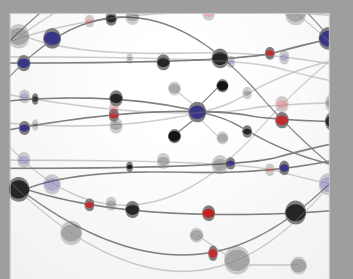

\section{Rotating \\ Machinery}

The Scientific World Journal

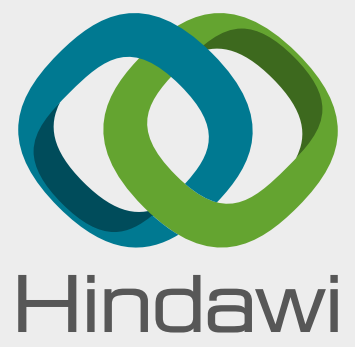

Submit your manuscripts at

www.hindawi.com
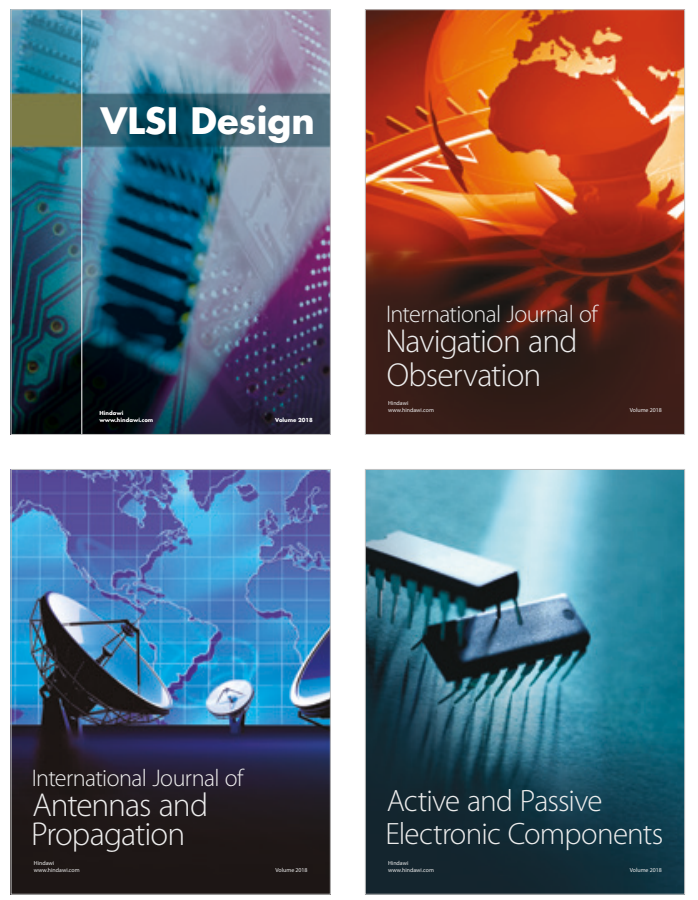
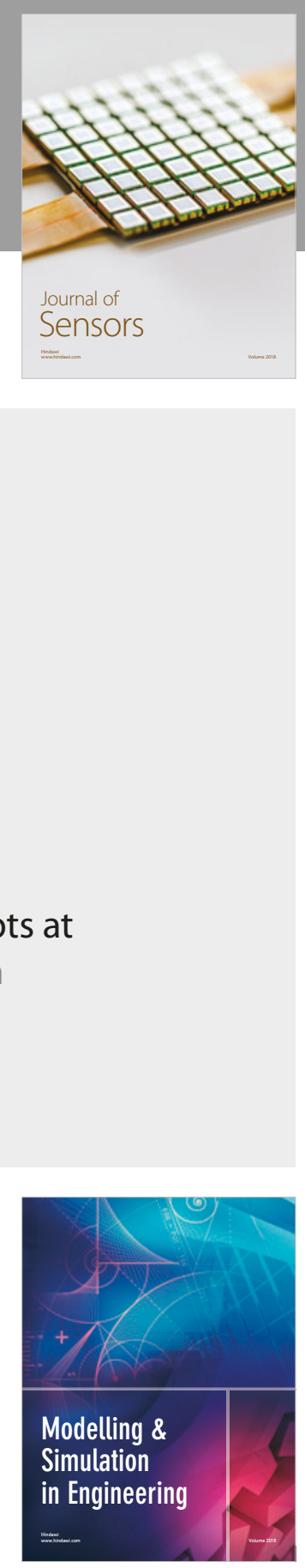

\section{Advances \\ Multimedia}
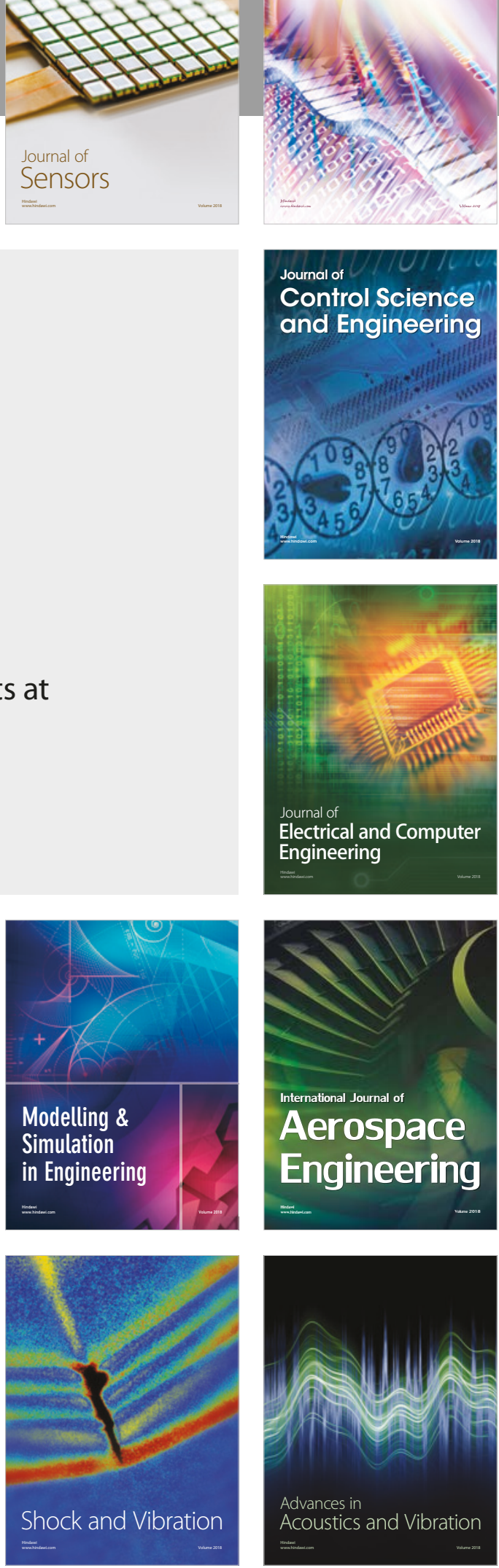